\title{
Desenvolvimento, educação e direitos humanos ${ }^{1}$
}

\author{
Álvaro Laborinho Lúcio ${ }^{\mathrm{i}}$ \\ Universidade do Minho, Portugal
}

\begin{abstract}
Resumo
Este artigo analisará, ainda que genericamente, o sentido e o valor do desenvolvimento e dos direitos humanos no contexto global atual. Aqui se discutirá o lugar do sujeito, a sua autonomia enquanto pessoa, a sua condição de cidadão e o seu papel nas democracias modernas. Adiantar-se-á, como hipótese, que, na relação ensino-aprendizagem, importará prosseguir um triplo objetivo, centrado no saber pensar, no saber escolher e no saber fazer. Noutro plano, cumpre olhar o conjunto dos temas em diálogo sem esquecer a questão da exclusão social, entendida aqui como negativo dos direitos humanos e do desenvolvimento. Concluir-se-á que a existência dos direitos humanos reclama um compromisso ético, integrando a busca da igualdade, isto é, do reconhecimento do outro, e do 'outro do outro', na sua autonomia e diversidade, como sujeitos de direito e de direitos. Daí a necessidade de educar para os direitos, que significa educar para os direitos do outro. Para os direitos enquanto instrumento de convivência entre sujeitos livres e também para a consciência do valor dos direitos coletivos.
\end{abstract}

Palavras-chave

Direitos Humanos; Educação; Desenvolvimento; Democracia

\section{Introdução}

Nestes tempos de particular incerteza e complexidade, dos quais resultam bem justificadas preocupações a vários níveis, é como problema, 
isto é, como questão aberta, que procurarei partilhar uma breve reflexão pessoal sobre o tema - Desenvolvimento, Educação e Direitos Humanos com ela assinalando, ainda que modestamente, a passagem de mais um aniversário da aprovação, pela Assembleia Geral das Nações Unidas, da Declaração Universal, exatamente numa época em que a solidez dos três pilares geracionais dos Direitos Humanos se encontra seriamente abalada.

\section{A Declaração de 1948 e o direito ao desenvolvimento}

A aprovação da referida Declaração traduziu, como se sabe, e a despeito das críticas (nomeadamente de natureza ideológica) que a acompanharam, uma demonstração de confiança no Direito, nos Direitos, no próprio Estado de Direito. Comemorá-la significa, por isso, também, a renovação do compromisso original com o reconhecimento da pessoa como sujeito de direito e de direitos, revestida de personalidade jurídica autónoma e afirmada no respeito pelo valor da dignidade humana. De uma dignidade "enquanto dimensão intrínseca do ser humano", na feliz expressão de Canotilho2.

É, aliás, este reconhecimento que, projetado em múltiplas manifestações posteriores, não deixará jamais de se apresentar como inspirado nas quatro liberdades de Roosevelt, quais sejam a liberdade de expressão, a liberdade religiosa, a liberdade contra a miséria, a liberdade contra o medo. São elas, na sua expressão potenciadora de direitos, que constituem os caboucos sobre os quais se ergueu a trilogia dos direitos civis, políticos e sociais e que, por via daquele compromisso, parecia terem-se por definitivamente inegociáveis.

Não é disso, porém, que estamos hoje seguros. Em pouco tempo, dirse-ia, num ápice, tudo mudou no nosso espaço de relação, onde se geram e se fortalecem as convicções.

Em pouco mais de vinte anos desabou o Muro de Berlim, rasgando-se na queda, além do mais, novos horizontes geográficos, políticos, económicos, culturais e sociais a uma Europa que procurava iniciar, ainda que titubeantemente, a experiência de uma transição estratégica da sua dimensão essencialmente económica, para uma verdadeira comunidade de natureza política. 
O desenvolvimento libertara-se de um significado redutor, oriundo do pós-guerra e coincidente com o de crescimento económico, para adquirir, no advento da terceira geração dos direitos humanos, o estatuto de objeto de um verdadeiro direito fundamental dos cidadãos. Colocada no centro, a pessoa humana passava a constituir a medida de todas as coisas e, assim, ao mesmo tempo, o objetivo essencial e o limite último ao próprio desenvolvimento. Este, por isso mesmo, abandonava a sua imaginosa adjetivação caracterizadora, não necessitando mais de se afirmar como 'harmonioso', 'ecologicamente equilibrado', 'sustentável', ou de 'rosto humano'. Agora, como objeto de um direito fundamental, o desenvolvimento incorporava já, na sua designação, todas essas dimensões, que passavam, assim, a constituir elementos da sua definição, e a revelar-se, por isso, pleonásticas na caracterização daquele 3 .

Em Portugal acreditava-se na Europa. Delors fazia-nos crer nas virtudes e nas possibilidades de uma verdadeira "coesão económica e social" e a União Monetária apresentava-se aos olhos de muitos como um passo decisivo e indispensável no caminho para uma almejada união política. Falava-se de cidadania europeia e incorporava-se os Direitos Humanos nos estatutos identificadores da União.

Com o desenvolvimento, implantou-se e expandiu-se a 'sociedade da informação', do 'conhecimento', da 'inovação' e das 'novas competências'. Assistiu-se ao boom das modernas tecnologias e à rápida generalização do acesso a muitas delas, o que, em si, se inscrevia, sem mácula, na coluna dos valores positivos a creditar a favor do próprio desenvolvimento.

Enquanto isto, longe de um criterioso acompanhamento crítico, a globalização da economia e, sobretudo, o triunfo instalado de uma dimensão teológica progressivamente atribuída ao mercado e às suas regras, fizeram ruir as tradicionais referências ideológicas, não faltando mesmo quem se apressasse a proclamar, desde logo, o Fim da História e quem viesse decretar para todo o sempre, a liquidação da utopia.

Ao militante de causas vinha suceder agora o consumidor de coisas, enquanto o ideal, futuro e incerto, da garantia de 'os direitos para todos' cedia perante o fascínio das promessas de uma aparente segurança garantida a cada um, aqui e já. Na verdade, antes, perante uma tradicional estratificação sociopolítica desenhada na vertical, com osmose entre os respetivos estratos, fácil seria sentir na base o peso do poder e da opressão oriundas do topo, e 
natural era fazer repercutir, em cima, os efeitos provocados pela reação gerada na base. A divisão de campos tornava-se naturalmente ideológica e era o estímulo criado pelo apelo à ideologia que inspirava, designadamente os mais ativistas e as próprias elites, a partilharem com várias outras camadas da população qualquer dos espaços da pirâmide social.

\section{Uma nova ética e novas políticas de pendor mercantil}

A tendência dos dias modernos revelou-se bem diversa.

A uma estratificação com fluxos de comunicação vertical, veio a suceder um desenho sociopolítico horizontal. A informação, os mercados e o hiperconsumo, permitem agora como que uma confortável incomunicabilidade estratégica e aparentemente consensual entre os grandes estratos. Na base, distante do poder económico e político, despida de uma visão crítica, ideológica, tanto sobre o mundo e a vida, como até sobre os acontecimentos do quotidiano, habita uma massa deslumbrada, palpitando entre um gratuito e irresponsável direito à opinião e uma felicidade ali ao pé, prometida nos anúncios publicitários, garantida pelo crédito bancário e moralmente legitimada pela aceitação geral.

No topo, sem graves perturbações colocadas pela discussão em torno da essência das coisas, decide-se sobre o destino dos países, da Europa e do mundo!

Debaixo da base reanima-se um lumpen de pobreza e de marginalidade, remetido para o domínio das categorias concetuais, de extração sociológica, sem representação, e acomodado num campo de visão estatística que, progressivamente, o vai avaliando em percentagens de recuperação tidas por toleráveis e, assim, legitimadoras do statu quo.

Nesta perspetiva, as elites tendem a fixar-se em cima, enquanto a participação cívica e política própria da base se vai tornando cada vez mais frouxa.

A democracia representativa cumpre periodicamente o seu trajeto chamando todos a eleições cuja vitória se joga, quantitativamente, mais na base do que no topo, e, ali, em nome da preservação do já adquirido, de um prazer sem exigência, da manutenção da ordem e da segurança contra o risco, bens que vêm, assim, a preencher, facilmente, o cardápio das promessas eleitorais. 
Na expressão de Lipovetsky (1994), temos aí "o culto da esfera privada e a indiferença em relação ao que é público, o poder total do dinheiro e a democratização da corrupção" (p. 230).

Assim se afastaram os cidadãos da política e do político, não sendo de prever, ainda que a prazo, que tal venha a revelar-se positivo, nomeadamente quando se tratar, como é agora o caso, de renovar, no seu próprio interesse, a política e o político.

Neste contexto, e em contraciclo, o 11 de Setembro, de 2001, veio fechar o tempo político aberto com o derrube do Muro e com o termo da Guerra Fria, conferindo maior peso à chamada 'sociedade do risco' e reabrindo novos e violentos conflitos de contornos imprecisos, mas que alguns se apressaram a adivinhar, preocupantemente, como anunciadores, a ocidente, do fim do multiculturalismo.

As contradições começavam a surgir, a fé a desvanecer-se, os direitos a relativizar-se.

O fragmentarismo, oriundo da diversidade social e humana, perdia força na relação dialógica com a homogeneização tributária do movimento de globalização, agora apoiado por reivindicações de segurança. Quase impercetivelmente, a afirmação de uma quarta geração de direitos humanos, mais ligada aos direitos do quotidiano, desviava a atenção das sucessivas interrogações sobre a validade universal dos direitos humanos de primeira e segunda gerações, e permitia que se abrisse campo para uma tolerância silenciosa quanto à violação de vários destes.

De acordo com o pensamento, discutível mas não desprezível, de Haarscher (1997), já dirigida à terceira geração dos direitos, "corre-se o risco de dar a primazia a vagos direitos dos povos (...) sobre a protecção precisa, aqui e agora, do indivíduo, sobre a luta contra o despotismo. Situação eminentemente confortável [prossegue] para todos os autocratas prontos a defender o 'progresso' e a 'autenticidade' das tradições não ocidentais (...) deixando na sombra (...) os direitos verdadeiros" (p. 53).

Entretanto, tudo veio a culminar na crise gerada nos mercados financeiros e na repercussão sensível desta nas finanças e nas economias dos Estados e dos cidadãos, arrastando consigo, nos mais frágeis, uma profunda crise social que, aparentemente, não deveria compadecer-se com 
uma atitude passiva de espera pela regeneração do mal, sem qualquer tentativa séria de intervenção sobre as verdadeiras razões deste e sobre as suas consequências no futuro a curto, a médio e a longo prazo. O terreno de discussão e as arenas de intervenção estavam, porém, muitas delas, ao abandono.

É assim que, quanto às causas, várias são, ainda hoje, as tentativas de uma sua identificação credível, sublinhando uns, principalmente, "os erros ínsitos nas políticas económicas e financeiras; outros (...) as debilidades estruturais das instituições políticas, económicas e financeiras; [não faltando, todavia, quem, indo mais fundo, as atribua] a cedências de natureza ética, ocorridas a todos os níveis, no contexto de uma economia mundial cada vez mais dominada pelo utilitarismo e pelo materialismo" (Pontifício Conselho Justiça e Paz , 2011, p. 5).

$\mathrm{Na}$ origem do problema, inscrevem outros, por fim e na mesma linha de pensamento, "um liberalismo económico que rejeita regras e controlo" e que, definindo "a priori as leis do funcionamento do mercado e do desenvolvimento económico, sem as confrontar com a realidade, corre o risco de se tornar um instrumento subordinado aos interesses dos países que gozam efectivamente de uma posição de vantagem económica e financeira" (Pontifício Conselho Justiça e Paz , 2011, p. 8). Posição, esta, que passa a definir outras centralidades de poder e de decisão e, a partir delas, outras referências, nomeadamente em termos de valores e de culturas. A Pessoa Humana perde a sua posição no centro, tende a tornar-se periférica e, assim, a ver reduzida a sua dimensão de sujeito autor e participante.

Neste processo acelerado de mudança, o tradicional poder de decisão política deslocou-se para instâncias só simbolicamente representativas, distantes dos cidadãos concretos, que, desse modo, viram menorizada a sua dimensão de autores comprometidos e críticos do seu próprio tempo e das opções que este impunha que fossem tomadas. As Pessoas desligaram-se progressivamente dos próprios Estados, que, por seu turno, se desterritorializaram, acomodando-se, obedientemente, junto dos centros de decisão.

Aí, porém, escasseavam os cidadãos, sendo que, em termos europeus, foi a 'cidadania europeia' a ver-se transformada, do pressuposto que devia ser, em objetivo discreto que a realidade tem mostrado ser 
despiciendo concretizar. $\mathrm{Na}$ verdade, ao discurso retórico, não veio a corresponder um significativo aumento de capacidade modificadora reconhecida aos cidadãos. Os tempos deixaram de ser os da política. Muito do poder transitou para o campo da economia, da finança e dos mercados, que se impõem à escala global. A tradicional dimensão axiológica típica dos modelos políticos de organização social e, mais concretamente, das democracias ocidentais, cedeu o passo às regras próprias da competição e da competitividade, em geral neutras em matéria de valores. Instalou-se, na base, aquilo que Eco (2007) designa de "regimes de facto", promotores de indiferença, estranhos a qualquer apelo oriundo de uma cidadania verdadeiramente ativa e poderosa. É a esse propósito que, no contexto português, D. Manuel Clemente lembra que transitámos de um 'penso, logo existo', de extração cartesiana, e acomodado no relevo a conceder à razão, para um hedonista 'sinto, logo existo', libertador das emoções e confessemo-lo - das responsabilidades. A questão, porém, agravou-se ainda mais com a passagem para um desistente e mais perigoso "não penso, logo ajo", tributário de um pensamento único, isto é, de uma ausência de pensamento, elevada à condição de garante de estabilidade, de previsibilidade e de segurança.

Ora, é este cidadão que, em vez de ter acrescentado ao "penso, logo existo" um "pensas, logo existes", desconformado da sua relação com o outro e do reconhecimento por si próprio da importância do outro, que persiste em continuar a desprezar o significado do próprio pensamento, para se circunscrever apenas à ação, uma ação, em regra, determinada por propósitos que lhe são estranhos.

\section{Regresso aos direitos, cidadania e educação}

Será, pois, o que referi atrás que urge afrontar e superar, começando por regressar, desde logo, ao terreno ainda valioso dos Direitos Humanos, sendo certo que superá-lo constitui pressuposto essencial para instilar qualidade, desde logo cívica, aos que se proponham, nos nossos dias, pensar e agir responsavelmente.

E esta é, antes de tudo, uma questão de cidadania! 
O que, evidentemente, requer uma reflexão dirigida aos temas ou tópicos centrais de compreensão da própria cidadania, começando, desde logo, por recolher desta uma conceção dinâmica que reserve um papel muito mais ativo para o cidadão, traduzido na "participação directa nos negócios públicos da comunidade" (Crouch, 1996, p. 2, cit. em Menezes, 2011, p. 109), permitindo ao indivíduo "sentir-se envolvido e identificado com o destino individual e colectivo, agindo sobre os desafios reais dos homens e das mulheres à escala onde os problemas se colocam tentando ultrapassar o sentimento de impotência que tantas vezes nos assola, enfim, entendendo a cidadania como sendo a crença na nobreza e na possibilidade do político" (Crouch, 1996, p. 2, cit. em Menezes, 2011, p. 109).

Tudo, afinal, no pressuposto de que "uma verdadeira democracia é aquela em que os cidadãos possuem - justamente - o sentimento de ter um real poder político, mesmo mínimo", para usar os termos de Farouki (2004, p. 172).

E este constitui o núcleo da questão, na medida em que "a partir do momento em que tomam consciência do facto de que a rede no poder se difundiu de tal forma que será escusado querer mudá-la, (...) ou desde que compreendam que o verdadeiro poder não está nas mãos dos representantes do povo, os cidadãos desinteressam-se de uma acção política que sabem ser ineficaz" (Farouki, 2004, pp. 172-173).

Por isso que, para pensadores como Touraine (2005), "nenhum problema político [seja] mais importante... do que a procura de um novo modelo de intervenção política, que não prejudique a competitividade mas proteja a população contra a brutalidade de uma economia liberal sobre a qual a maioria dos países não tem nenhuma capacidade de influência" (p. 36).

É esta noção de cidadania que, nas palavras de Fernandes (2004), "apresenta uma dupla dimensão, [constituindo] a base tanto do direito a viver em sociedade, como da obrigação de desenvolver uma actividade colectiva" (p. 181) 4 .

Uma cidadania, afinal, de direitos e de responsabilidades, ela própria, impulsionadora de um retorno ao conceito de desenvolvimento enquanto objeto de um direito fundamental dos cidadãos. Cidadania que, na linha de pensamento de Schnapper (1994, pp. 94-95), repouse na garantia de que os cidadãos disponham de todos os meios necessários para exercerem 
concretamente os seus direitos, nomeadamente de uma educação que proporcione a todos as capacidades intelectuais e cognitivas para participarem realmente na vida pública, política, económica, social e cultural.

$\mathrm{O}$ que nos coloca perante os desafios a dirigir à Educação e nos remete necessariamente para o interior da Escola.

Com efeito, num espaço marcado por uma densa complexidade e no qual a diversidade, que a massificação do ensino transportou de fora para dentro, tende a constituir a regra ou o padrão, impõe-se inscrever a tarefa urgente de passar da massificação à democratização, resultado que está longe de se ter por atingido, se não mesmo por querido enquanto objetivo. Desde logo, porque a transição haverá de fazer-se bem menos pela via da normalização do habitat interno, e muito mais pelo reconhecimento da individualidade de cada um dos seus agentes, incorporando-se aquela diversidade e aceitando-se como natural a própria complexidade, num esforço comprometido com o desígnio de garantir a convivência entre exigências de autonomia crítica e de solidariedade entre as pessoas. O que, realmente, não representa novidade de tomo. De facto, já há mais de cinco décadas, Sanderson e a Escola de Oundle consideravam que "só a actividade complexa é criadora" (Silva, 1941, p. 125), enquanto outros, como Postman (2002), defendiam que "a diversidade é a narrativa que descreve como as nossas interações com todo um conjunto de pessoas diferentes nos transformam naquilo que somos" (pp. 168-169), retirando daí constituir ela "uma narrativa fecunda à volta da qual se pode organizar o ensino dos jovens" (p. 95). O que, afinal, não difere da linha de reflexão de Galichet (2005, p. 112; ver também Barbosa, 2006, p. 78), para quem "as crianças encerradas em escolas de uma só classe, de uma só cultura, estão privadas de cidadania, quer dizer, da dimensão central dessa cidadania que é a confrontação com a alteridade social, cultural ou intelectual de colegas que são, no entanto, seus concidadãos".

Parece, assim, que na estrita relação entre o ensino e a aprendizagem importará prosseguir um triplo objetivo, centrado no saber pensar, privilegiando o conhecimento e a reflexão crítica; no saber escolher, valorizando a autonomia pessoal e a responsabilidade; e no saber fazer, dando corpo, agora sim, à importância da técnica e das competências.

Não podendo, portanto, deixar de perspetivar-se a Educação e a Escola como 'instrumentos' para a cidadania e para a democracia, delas 
haverá de reclamar-se formação de pensamento crítico, promotor de dissidências responsáveis. Não vale, assim, aceitar sem análise a conceção por força da qual cabe à escola e à educação formal assumirem a condição de instrumento na 'sociedade de informação e do conhecimento', educando apenas para o desenvolvimento económico. Como bem assinala Azevedo (2007, p. 23), esta não é uma conceção politicamente neutra... E é urgente ter consciência disso.

Com efeito, uma escola responsavelmente promotora de pensamento crítico terá, antes do mais, de se instituir por si mesma e de reivindicar uma autonomia indispensável à formação da sua identidade própria. Não uma autonomia reclamada em nome do poder burocrático da escola, mas uma autonomia reconhecida em razão de valores democráticos que reclamam uma educação ao serviço das pessoas, de todas as pessoas. Autonomia reconhecida a uma escola - como sustenta Barbosa (2006, p. 78 e 79) "pensada e estruturada tendo em vista a sistemática aprendizagem da cidadania moderna", na ideia de que "uma das funções essenciais da escola consiste em contribuir para a formação de cidadãos e de cidadãs responsáveis e solidários... não de sujeitos administrados e conformados, mas de cidadãos protagonistas do destino das suas vidas públicas e privadas". Uma escola responsável pelo seu projeto educativo que, assim, saiba emergir de verdadeiras comunidades educativas que o tomem como desígnio seu e o transformem em projeto com e para o futuro.

Tudo na procura de uma estratégia educativa que, finalmente, sem perda de horizontes que alarguem a reflexão, prepare também, de forma exigente, para os desafios e para os benefícios da globalização e da competitividade.

Postman (2002, p. 28), comentando o pensamento de Thomas Jefferson sobre o direito à vida, à liberdade e à felicidade, aventa que "dificilmente teria ocorrido a este homem, como acontece com os líderes políticos dos nossos dias, que os jovens deveriam aprender a ler com o único propósito de aumentar a sua produtividade económica". Para concluir afirmando que Jefferson "servia a um deus mais sagaz"! É esse "deus", ou pensamento, que importa reinventar. Ou, melhor, não deixar morrer.

No entanto, jamais poderá educar-se para a cidadania sem antes se tomar o espaço ecológico da escola como o lugar privilegiado para viver o exemplo de uma verdadeira cidadania para a educação. 
Nesta linha de pensamento, Afonso (2001) refere que "só através do aprofundamento da democracia nos mais diversos domínios e espaços públicos e privados da vida em sociedade podemos ampliar o próprio conceito de cidadania" (p. 16). Esta reflexão conduz-nos à necessária conclusão de que Educação e Escola constituem não só conceitos diferentes, como à de que a relação entre ambas apenas poderá viver-se com êxito a partir do respeito devido à autonomia própria de cada uma e aos objetivos diferenciados que lhes são cometidos.

Este é um bom tópico para o regresso ao terreno do político, para a consideração aí da 'transformação da política' e para o retorno aos desafios do desenvolvimento.

Para Innerarity (2005) "um objectivo prioritário da transformação da política é a consecução de um novo equilíbrio entre as tarefas privadas e as tarefas públicas... sendo estas últimas as que exigem decisões colectivas" ( $p$. 200). Trata-se de diminuir o peso da política hierarquizada, institucional e redentora, substituindo-a por uma política heterarquizada, de funcionamento em rede, comunitária e de corresponsabilização, capaz de intervir em sociedades complexas (Innerarity, 2005, p. 200).

Por sua vez, Fernandes (2004) afirma que "para realizar esse complexo objectivo, as sociedades parecem carecer de um forte investimento em cultura cívica e em cultura política, sem as quais não é possível desenvolver uma verdadeira ação comunicacional em democracias dialógicas" (p. 54).

É assim, na conformação do objeto próprio desta cultura cívica e desta cultura política, que somos reconduzidos ao tema da centralidade do sujeito e do cidadão.

Por aqui passa, necessariamente em fundo, o conceito de good governance, incluído na lista de pressupostos do sucesso da globalização e do próprio desenvolvimento. Boa governação, essa, todavia, necessariamente assente em princípios básicos como "a democracia, a equidade social, o respeito dos direitos humanos e o primado da lei" (Comissão Mundial, 2005, p. 74). Aliás, como resulta do texto da Declaração do Milénio das Nações Unidas (2000), onde pode ler-se que "não pouparemos nenhum esforço para promover a democracia e reforçar o Estado de Direito, 
assim como o respeito dos direitos humanos e das liberdades fundamentais reconhecidas no plano internacional, incluído o direito ao desenvolvimento".

Todavia, estaremos certamente de acordo quanto ao facto de que o primeiro decénio do milénio e os primeiros passos do segundo não souberam incorporar um verdadeiro sinal de esperança de que seja aquele o caminho. O que apenas significa a necessidade de um maior empenhamento dos povos e uma mais efetiva intervenção crítica destes para o conseguir.

\section{Exclusão social, educação para os direitos e desenvolvimento}

Peguemos, como tema nuclear a reclamar uma intervenção urgente e efetiva, na exclusão social. Exclusão olhada não apenas como forma de desigualdade social, mas enquanto limitação do acesso à condição de cidadania, de uma cidadania vista não só como uma condição política para a ação, mas, sobretudo, como expressão da dignidade de todos e de cada um de nós. Uma cidadania tida, nas palavras de Ginner, como verdadeira condição moral. $O$ que nos conduz à consciência de que a exclusão ultrapassa, em muito, uma estrita dimensão económica, representando no limite a própria morte civil dos excluídos, reconduzindo-se, por isso, a uma verdadeira questão de Direitos Humanos.

É Galbraith quem afirma que "importa que seja reconhecido que não há nada que negue de forma tão compreensiva as liberdades individuais como a ausência de recursos materiais" (cit. em Pedroso, 1998, p. 143). O que vem a comprometer, afinal a própria democracia, com a "concretização articulada das três gerações de direitos", conferindo hoje particular relevo aos direitos sociais.

É aí que o património inalienável dos Direitos Humanos vem a revelarse comprometido não apenas com a natureza política da sua progenitura, mas também com a dimensão ética da sua legitimação social e humana. Daí que deva partilhar-se o pensamento de Rocha (2001, p. 204) para quem "falar de ética hoje é falar sobretudo de justiça, isto é, dos princípios, das condições e dos conteúdos susceptíveis de definir uma sociedade justa", de uma "justiça entendida como o reconhecimento e o respeito pela dignidade de cada um e a rejeição da situação de dominação e de violência" (idem). 
A partir daqui poderemos então concluir que a existência dos Direitos Humanos reclama, também ela, um compromisso ético, do ponto em que thes cabe integrar, como pressuposto da sua própria validade, a busca simultânea da igualdade, isto é, do reconhecimento do outro, e do "outro do outro" (ver Reguera, 2006), na sua autonomia e diversidade, como sujeitos de direito e de direitos.

\section{Na bela reflexão de Bocchi e Ceruti (1991),}

no outro não descobrimos só um limite, alguém ou alguma coisa de irredutível ao nosso ponto de vista, de insituável nos quadros, amiúde estreitos, onde nos fechámos. De modo mais radical, o outro torna-se o próprio motor do nosso desenvolvimento, o impulso e a unidade de medida de um confronto incessante, graças ao qual construímos e realizamos potencialidades das quais não tínhamos no entanto consciência (p. 157).

E, daqui, "à luz [destas] novas formas de relação entre si e o diferente de si", partem os autores para a conclusão de que "as próprias 'vitória' e 'derrota' adquirirão novos valores: mais próximas do viver em conjunto, do desenvolver em conjunto, do co-desenvolver" (Bocchi e Ceruti (1991, pp. 158159).

E basta dizê-lo para que logo se deixe ver como importa voltar a chamar a capítulo a Educação e a Escola, e a relação destas com os temas centrais dos Direitos Humanos e do Desenvolvimento.

Para logo começar por reter que educar efetivamente para os Direitos Humanos significa, em síntese, educar para os direitos. Para os direitos do outro. Para os direitos enquanto instrumento de convivência entre sujeitos livres. Para os direitos individuais, evidentemente, mas também para a consciência do valor dos direitos coletivos. Dos direitos do presente e dos direitos do futuro. E então, talvez aí, no espaço privilegiado da educação e da escola, se encontre o terreno apropriado para se restaurar a procurada relação saudável entre Desenvolvimento e Direitos Humanos, como valores e conceitos fortes, incompatíveis com teorizações e discursos moles, e incapazes de se subordinarem a desígnios estritamente materiais e de mera conjuntura que neguem a centralidade da Pessoa Humana na formulação dos objetivos a prosseguir em nome da coletividade.

Por isso que tenha de exigir-se da escola que comece, ela própria, por se afirmar como espaço de inclusão, de esvaziamento da discriminação, 
exemplar na assunção saudável da diversidade e da heterogeneidade, e promotor de condutas solidárias entre diferentes, rejeitando, desde logo, projetos que, sob a capa de um desejável reforço de exigência e de qualidade, venham a negar precocemente a inclusão de todos, enquanto direito e como objetivo inalienável do sistema.

Essa batalha não pode ser perdida, como preveem Steiner e Ladjali (2003, p. 76) que aconteça, ou tenha mesmo acontecido. E, perdida, segundo ele, tanto "porque há muitos seres humanos que amadurecem lenta e tardiamente", como também porque "há aqueles que se apagam para sempre na escola".

Com efeito, como poderá educar-se para os Direitos Humanos sem que antes se tenha inscrito na identidade e nas práticas do quotidiano da escola exatamente uma cultura dos direitos? Não uma cultura - repete-se que anule a exigência, o sentido de responsabilidade, a disciplina, o respeito pela hierarquia, mas uma cultura que estimule a solidariedade, que desenvolva o sentido de cada um na sua projeção no outro e que permita, assim, logo no interior da escola, uma efetiva aprendizagem da inclusão, contra a exclusão.

Afinal, em grande parte, é isso educar para a cidadania. Mas para uma cidadania material e ativa. Uma cidadania de direitos e de responsabilidades, capaz de dar corpo a uma verdadeira e efetiva democracia participativa. Seja enquanto depositária do nosso compromisso original com o respeito pelos Direitos Humanos. Seja como campo de ressonância ética para a recriação do Desenvolvimento.

\section{Reflexões finais}

Por ser difícil o caminho, vale a pena invocar aqui a preocupação manifestada por Roszak (1986, pp. 62-63) quando, começando por proclamar que "o diálogo humano livre, o percorrer de todos os caminhos a que nos leva a agilidade da mente, está na base da educação", adianta que "se os professores não têm tempo, encorajamento ou sagacidade para fornecer esta base; se os alunos estão demasiado desmoralizados, entediados ou distraídos para prestar a atenção que os professores deles requerem, então é esse o problema educacional que terá de ser resolvido". 
Servindo-nos das palavras de Haarscher (1997), concluiremos que para que as liberdades

não culminem num hedonismo radical (...) é necessário que seja instalado um dispositivo de segurança sem o que a ladeira de desencanto que leva ao niilismo de que 'tudo é permitido', 'tudo é possível', será descida antes que o intelectual 'humanista' tenha sequer tempo de se virar. Uma tal segurança [remata] é a educação sobre a qual será agora necessário concentrar as investigações... (p. 166).

\section{Notas}

1 Este texto inclui várias passagens de outros, também do autor, sobre temas com este relacionados.

2 Trata-se, como ensina Garcia (1998), de afirmar perentoriamente, de um lado, o "indivíduo como sujeito de direitos e deveres, dotado de uma personalidade jurídica que é emanação da sua própria ontologia e, de outro, uma proibição clara da instrumentalização do homem pelo homem". Reconhece-se, assim, ao "indivíduo a faculdade de, em todos os lugares, reivindicar a 'sua' personalidade jurídica, ciente de que, em todos os lugares, Ihe é garantido o estatuto de sujeito de direitos e deveres".

3 Não faltou, é certo, quem viesse alertar para os riscos de uma atitude que acolhia com excesso de fé aquilo que uma racionalidade crítica sempre imporia que se acompanhasse cautelosamente.

4 Atividade, esta, que, de novo na esteira de Touraine, deverá, então, assentar em três ideias fundamentais: a primeira, a de que a mundialização da economia não dissolve a nossa capacidade de ação política; a segunda, a de que as categorias mais desfavorecidas não atuam só sublevando-se contra a dominação, mas igualmente reclamando direitos, em particular direitos culturais, e afirmando, por isso mesmo, uma nova conceção inovadora da sociedade; e finalmente a terceira, a ideia de que a ordem institucional é ineficaz e será mesmo repressiva, se não se apoiar em reivindicações de igualdade e de solidariedade. Dir-se-ia que, a partir daqui, poderemos ser convidados a tentar fazer conviver, ao lado de uma lógica de ordem e de desordem, de norma e de transgressão, própria de um paradigma de regulação centrada, toda ela, no Estado, uma outra lógica, de ação social e política. De uma ação social e política heterogénea e heterárquica assente, não numa regulação centrada exclusivamente no Estado, mas comprometida com o peso a reconhecer ao cidadão e à cidadania, recolhendo desta uma conceção dinâmica, que reserve um papel muito mais ativo para o cidadão. 


\section{Referências}

Afonso, A. (2001). Globalização, crise do Estado-nação e reconfiguração das cidadanias: Novos desafios às políticas de educação. In M. Barbosa (Org.), Educação do cidadão. Recontextualização e redefinição (pp. 11-24). Braga: Edições APPACDM.

Azevedo, J. (2007). Sistema educativo mundial. Ensaio sobre a regulação transnacional da educação. Vila Nova de Gaia: FML.

Barbosa, M. (2006). Educação e cidadania, renovação da pedagogia. Amarante: Agora.

Bocchi, G., \& Ceruti, M. (1991). Os novos jogos planetários. In E. Morin, G. Bocchi \& M. Ceruti, Os problemas do fim de século. Lisboa: Editorial Notícias.

Comissão Mundial Sobre a Dimensão Social da Globalização (2005). Por uma globalização justa - Criar oportunidades para todos. Oeiras: Celta.

Crouch, C. (1996). Social and economic citizenship below the nation stare. In a world of migration. Conference European Fórum. Florence: European University Institute.

Eco, U. (2007). A passo de caranguejo. Lisboa: Difel, Lisboa.

Farouki, N. (2004). Os dois ocidentes. Lisboa: Instituto Piaget.

Fernandes, J. T. (2004). Democracia, novos desafios e novos horizontes. Oeiras: Celta.

Galichet, F. (2005). L'école, lieu de citoyenneté. Paris: ESF.

Garcia, M. G. (1998). A garantia da compreensão jurídica da pessoa humana. In A. Ribeiro, A. Betencourt \& A. Almeida Santos (Orgs.), Repensar a cidadania, nos 50 anos da declaração universal dos direitos humanos (pp. 48-49). Lisboa: Editorial Notícias.

Haarscher, G. (1997). A filosofia dos direitos do homem. Lisboa: Instituto Piaget.

Innerarity, D. (2005). A transformação da política. Lisboa: Teorema.

Lipovetsky, G. (1994). O crepúsculo do dever. Lisboa: D. Quixote.

Menezes, M. (2011). Analítica da cidadania e o serviço social na atualidade. Da teoria à prática. Gestão e Desenvolvimento, 19, 115-138.

Pedroso, P. (1998). Direito à segurança social. In CIVITAS, Repensar a cidadania nos 50 anos da declaração universal dos direitos do homem (pp. 139-14). Lisboa: Editorial Notícias.

Pontifício Conselho Justiça e Paz (2011). Para uma reforma do sistema financeiro e monetário internacional na perspectiva de uma autoridade pública de competência universal. Lisboa.

Postman, N. (2002). O fim da educação. Redefinindo o valor da escola. Lisboa: Relógio d'Água.

Reguera, G. (2006). El valor de los otros - Más allá de la violencia intercultural. Madrid: Biblioteca Nueva.

Rocha, A. (2001). Justiça e direitos humanos. Braga: Centro de Estudos Humanísticos.

Roszak, T. (1986). The cult of information: The folklore of computers and the true art of thinking. New York: Pantheon. 
Schnapper, D. (1994). La communauté des citoyens. Paris: Gallimard.

Silva, A. (1941). Sanderson e a Escola de Oundle. Lisboa: Inquérito.

Steiner, G., \& Ladjali, C. (2003). Elogio da transmissão, o professor e o aluno. Lisboa: D. Quixote.

Touraine, A. (2005). Um novo paradigma - Para compreender o mundo de hoje. Lisboa: Instituto Piaget. 


\section{DEVELOPMENT, EDUCATION AND HUMAN RIGHTS}

\section{Abstract}

We provide a general review of the meaning and value of development and human rights under the global context of nowadays and actual society. Thereafter, we discuss the importance of the individual, its autonomy, its citizen condition and the role he plays in modern democracies. In the course of teaching and learning, the core lies in how to think, how to choose and the know-how. By the other hand, it is time to approach the social exclusion, itself an example of the negative side of human rights and development. Thus, we conclude that the existence of human rights claims an ethical commitment, being responsible for integrate the search of equality, meaning the acceptance of the other, and 'other of the other' in their autonomy and diversity, as individuals with rights. Hence the need to promote human rights education, highlighting that educating for human rights just means teach to other's rights and for rights as an instrument of coexistence between free individuals. Learn about individual rights, but also be aware of the value of collective rights.

Keywords

Human Rights; Education; Development; Democracy

\section{DESARROLLO, EDUCACIÓN Y DERECHOS HUMANOS}

\section{Resumen}

Se revisará la cuestión referida al sentido, el valor y el desarrollo de los derechos humanos en el contexto actual. Se tratará de conocer el lugar y papel que ocupa el sujeto, su autonomía y su condición de ciudadano en las democracias modernas. Se anticipa como hipótesis que, en relación al proceso de enseñanza y aprendizaje, será importante perseguir un triple objetivo centrado en el saber pensar, el saber seleccionar y el saber hacer. Otro aspecto fundamental será el de la exclusión social, tratada aquí como el 
lado negativo de los derechos humanos y del desarrollo. Se concluye que la existencia de los derechos humanos reclama un compromiso ético integrando la búsqueda simultánea de la igualdad, esto es, del reconocimiento del 'otro' en su autonomía y diversidad como sujetos de derecho y con derechos. De ahí la necesidad de educar para los derechos, que significa educar para los derechos del 'otro', para los derechos como instrumento de convivencia entre sujetos libres, para los derechos individuales y también para la conciencia del valor de los derechos colectivos.

Palabras clave

Derechos Humanos; Educación; Desarrollo; Democracia

Recebido em agosto, 2013

Aceite para publicação em outubro, 2013

i Escola de Direito, Universidade do Minho, Portugal

Toda a correspondência relativa a este artigo deve ser enviada para: Álvaro Laborinho Lúcio, Rua Edmundo de Bettencourt, n. ${ }^{\circ} 11,2^{\circ}, 3000-606$ Coimbra. E-mail: laborinholucio@gmail.com 